\title{
EPIDURAL BUPRENORPHINE FOR PAIN RELIEF AFTER SPINAL DECOMPRESSION
}

\author{
G. P. WILDE, A. J. WHITAKER, A. MOULTON \\ From Mansfield District General and Harlow Wood Orthopaedic Hospitals
}

\begin{abstract}
We report a prospective double-blind trial of the efficacy of a single epidural dose of buprenorphine on pain after spinal decompression. Postoperative pain was assessed by a linear analogue pain chart and by the additional requirement for analgesia.

The patients receiving buprenorphine were significantly more comfortable $(p<0.005)$ and required less analgesia in the first 12 hours after operation $(p<0.05)$ than the control group. This simple procedure is recommended as an effective and safe method of reducing pain.
\end{abstract}

Postoperative pain is of ten the most distressing part of a surgical procedure. Traditionally this has been relieved by narcotic analgesics given by injection both during and after the operation, but recent work has shown considerable increase in comfort when morphine is administered by an epidural route (Lanz et al. 1982; Stenseth, Sellevold and Breivick 1985). The use of epidural morphine, however, has been associated with a high incidence of side effects, of which urinary retention may be troublesome, with up to $64 \%$ of patients requiring catheterisation (Walts et al. 1985). Rechtine, Reinert and Bohlman (1984) showed that a single epidural dose of morphine given at the time of laminectomy rendered patients more comfortable in the postoperative period but that $50 \%$ of those receiving the drug required catheterisation.

Buprenorphine is a synthetic analgesic agent, closely related in structure to morphine, but with a weight for weight potency 40 to 50 times greater. It has powerful agonist and partial antagonistic characteristics and has been shown, when given parenterally, to have a duration of action approximately twice that of other

G. P. Wilde, FRCS, Orthopaedic Registrar and Spinal Research Fellow

A. Moulton, FRCS, Consultant Orthopaedic Surgeon

Mansfield District General Hospital and Harlow Wood Orthopaedic

Hospital, near Mansfield, Nottinghamshire NG18 4TH, England

A. J. Whitaker, FFARCS, Consultant Anaesthetist

Mansfield District General Hospital, West Hill Drive, Mansfield, Nottinghamshire NG18 1 PH, England.

Correspondence should be sent to Mr G. P. Wilde.

(C) 1988 British Editorial Society of Bone and Joint Surgery

$0301-620 X / 88 / 3089 \$ 2.00$

J Bone Joint Surg [Br] 1988;70-B:448-50. commonly used narcotic agents together with a significant reduction in side effects (Downing, Leary and White 1977; Kamel and Geddes 1978; Kay 1978).

We report a prospective comparison of a single epidural dose of buprenorphine against a placebo in a series of 50 patients undergoing spinal decompression. We assessed both analgesic properties and side effects.

\section{PATIENTS AND METHODS}

Fifty consecutive patients undergoing spinal decompression were selected at random to receive a single peroperative epidural dose of either buprenorphine or placebo. The choice of injection was unknown to all personnel involved in the care of the patients. For each patient a syringe, containing either $0.3 \mathrm{mg}$ buprenorphine in $10 \mathrm{ml}$ normal saline, or $10 \mathrm{ml}$ of saline alone was prepared on the day before operation.

General anaesthesia was administered by one of two consultant anaesthetists according to a standard proto$\mathrm{col}$, and all the operations were performed under the supervision of one of two consultant surgeons. Of the $\mathbf{5 0}$ patients, 29 had undergone fenestration of the spinal canal and discectomy alone, while 21 also had some form of bony decompression. In all cases, after adequate haemostasis had been achieved, and before wound closure, the contents of the prepared syringe were dribbled gently onto the exposed dura. The wound was then closed in layers, taking care not to remove the solution by swabbing or suction. No drains were used deep to the lumbar fascia but in obese patients suction drainage of the superficial layers was allowed at the discretion of the surgeon.

The trial solution was not given if there had been 
any perforation of the dura during the operation or if the patient had reported any allergy or sensitivity to buprenorphine.

Routine postoperative observation and care for all patients included analgesia on an "as required" basis. Postoperative pain was assessed from records of the total amount and timing of the analgesia required, and, on the first morning after operation, from the pain level assessed by a linear analogue scale.

The results were statistically analysed using the Mann-Whitney $U$ test as the data was non-normally distributed.

The protocol for the study had prior approval by the ethical committee of the Central Nottinghamshire Area Health Authority.

Anaesthetic protocol. Patients were pre-medicated with lorazepam 2 to $2.5 \mathrm{mg}$, droperidol $5 \mathrm{mg}$ and labetalol $200 \mathrm{mg}$, given 2 to 2.5 hours before the operating session. Induction of anaesthesia was achieved with either thiopentone or methohexitone in appropriate doses, together with phenoperidine 1 or $2 \mathrm{mg}$. Anaesthesia was maintained with nitrous oxide, oxygen and halothane in varying concentrations depending on the blood pressure and muscle relaxation achieved with curare. Postoperatively omnopon 10 to $20 \mathrm{mg}$ was prescribed to be given as required, with Ibuprofen $400 \mathrm{mg}$ as an alternative oral analgesic.

\section{RESULTS}

Four patients were excluded from the analysis (two from each group) because of either possible sensitivity to buprenorphine or dural perforation. There was no significant difference between the two groups with regard to age, sex, or duration of symptoms (Table I).

Table I. Comparison of the two groups of patients

\begin{tabular}{lll}
\hline & Buprenorphine & Placebo \\
\hline Sex & $15 \mathrm{M}-8 \mathrm{~F}$ & $14 \mathrm{M}-9 \mathrm{~F}$ \\
Age of patient in years, mean (range) & $41.3(16$ to 64$)$ & $38.2(19$ to 64$)$ \\
$\begin{array}{l}\text { Duration of symptoms in months } \\
\text { (mean } \pm \text { SD) }\end{array}$ & $16.5 \pm 14.6$ & $17.6 \pm 13.7$ \\
Number with tension signs & 15 & 14 \\
\hline
\end{tabular}

Patients receiving buprenorphine required significantly less omnopon during the first 12 hours $(p<0.05)$; the mean dose in the placebo group being twice that in the test group (Table II). Despite this increased dosage of analgesics, the linear analogue pain scores recorded on the first post-operative morning were very significantly higher in the control group $(\mathrm{p}<0.005)$. In addition there was a much longer interval before the first requirement for analgesia in the test group $(p<0.005)$. The mean period before the first administration of analgesia was more than 10 hours in the buprenorphine group, and four patients required no postoperative narcotic analgesia (Table II). After the first 12 hours, there was no significant difference in the total analgesic requirements of the two groups.

Table II. Results as regards levels of analgesia in the two groups

\begin{tabular}{lccl}
\hline & Buprenorphine & Placebo & $\begin{array}{l}\text { Significance } \\
\text { (Mann-Whitney }\end{array}$ \\
\cline { 2 - 3 } & Mean \pm SD & Mean \pm SD & U test) \\
\hline $\begin{array}{l}\text { Linear analogue pain } \\
\text { score }\end{array}$ & $3.7 \pm 2.3$ & $6.1 \pm 2.2$ & $\mathrm{p}<0.005$ \\
$\begin{array}{l}\text { Mean time before first } \\
\text { analgesia (hours) }\end{array}$ & $10.2 \pm 5.4$ & $5.3 \pm 3.2$ & $\mathrm{p}<0.005$ \\
$\begin{array}{l}\text { Omnopon in first } \\
\text { 12 hours (mg) }\end{array}$ & $20.0 \pm 19.0$ & $40.0 \pm 14.0$ & $\mathrm{p}<0.05$ \\
$\begin{array}{l}\text { Omnopon from 12 to } \\
\text { 24 hours (mg) }\end{array}$ & $23.0 \pm 22.0$ & $27.5 \pm 17.0$ & $\mathrm{NS}$ \\
$\begin{array}{l}\text { Omnopon from 24 to } \\
\text { 48 hours (mg) }\end{array}$ & $15.0 \pm 20.0$ & $8.5 \pm 14.0$ & $\mathrm{NS}$ \\
\hline
\end{tabular}

The complication rate was similar for the two groups, and in particular, urinary retention was not a problem. Only four of the 50 patients required catheterisation, and three of these had received placebo. There were no problems with hypotension or respiratory depression and no case of wound infection in either group.

\section{DISCUSSION}

Morphine applied directly to the epidural space is known to produce better analgesia than an identical dose given by intramuscular injection (Lanz et al. 1982). This is due to its action on specific spinal narcotic receptors and is unrelated to the serum concentration of the drug (Cousins and Mather 1984). Previous studies on the epidural administration of narcotics have usually concerned patients undergoing epidural anaesthesia via an indwelling cannula. Morphine has commonly been used but frequent side effects have been reported, especially urinary retention and pruritis (Walts et al. 1985; Stenseth et al. 1985).

In our study, a single peroperative epidural dose of buprenorphine was effective in controlling postoperative pain and was not associated with any undesirable side effects. We currently use this method of analgesia routinely for patients undergoing spinal surgery and believe that it is useful in the control of postoperative pain. 
We conclude that buprenorphine can safely be instilled into the epidural space after operation for spinal decompression, that a single dose of $0.3 \mathrm{mg}$ provides adequate analgesia for an average of 10 hours, and that this method does not cause post-operative urinary retention.

We wish to thank Ms Jackie Leach and Ms Valerie Rodgers of the pharmacy department at Mansfield General Hospital for their help in preparing the samples, Mr R. C. Mullholland FRCS for his encouragement and permission to include his patients in the study, $\mathrm{Dr}$ D. Naylor for her co-operation in the administration of the anaesthetics and Mrs Julie Herring for her secretarial assistance.

No benefits in any form have been received or will be received from a commercial party related directly or indirectly to the subject of this article.

\section{REFERENCES}

Cousins MJ, Mather LE. Intrathecal and epidural administration of oipoids. Anaesthesiology 1984;61:276-310.
Downing JW, Leary WP, White ES. Buprenorphine : a new potent longacting synthetic analgesic: comparison with morphine. $\mathrm{Br} J$ Anaesth 1977;49:251-5.

Kamel MM, Geddes IC. A comparison of buprenorphine and pethidine for immediate postoperative pain relief by the I.V. route. $\mathrm{Br} J$ Anaesth 1978;50:599-603.

Kay B. A double-blind comparison of morphine and buprenorphine in the prevention of pain after operation. Br $J$ Anaesth 1978;50:605-9.

Lanz E, Theiss D, Riess W, Sommer U. Epidural morphine for postoperative analgesia: a double-blind study. Anesth Analg 1982;61:236-40.

Rechtine GR,Reinert CM, Bohlman HH. The use of epidural morphine to decrease postoperative pain in patients undergoing lumbar laminectomy. J Bone Joint Surg [Am] 1984;66-A:113-6.

Stenseth R, Sellevold O, Breivik H. Epidural morphine for postoperative pain: experience with 1085 patients. Acta Anaesthesiol Scand $1985 ; 29: 148-56$.

Walts LF, Kaufman RD, Moreland JR, Weiskopf M. Total hip arthroplasty: an investigation of factors related to postoperative urinary retention. Clin Orthop 1985;194:280-2. 